\title{
The diffusion of $\mathrm{CO}_{2}$-brine storage based on stochastic partial differential equations
}

\author{
Liu Bin ${ }^{1, *}$, Wang Bo ${ }^{1}$, Li Zhuo $^{2}$, Lv Yanfang ${ }^{2}$ \\ ${ }^{1}$ Schlool of Electrical and Information Engineering, Northeast Petroleum University, Daqing 163318, China \\ ${ }^{2}$ Schlool of Earth Sciences, Northeast Petroleum University, Daqing 163318, China
}

\begin{abstract}
The migration of $\mathrm{CO}_{2}$ is stochastic in heterogeneous porous media. This paper considers the $\mathrm{CO}_{2}$ diffusion with the case of steady flow in heterogeneous porous media. The partial differential equations of $\mathrm{CO}_{2}$ diffusion in random velocity field are established based on the mass conservation equations of $\mathrm{CO}_{2}$ brine two-phase flow with the change of time scale and spatial scale under the influence of heterogeneity such as permeability and porosity. The random travel process of $\mathrm{CO}_{2}$ is quantified by joint probability distributions and joint statistical moments (mean and variance), and the diffusion model of $\mathrm{CO}_{2}$ particle in random velocity field is established under the condition of non-linear and immiscibility in heterogeneous porous media. The micro mechanism of diffusion in heterogeneous porous media is revealed by numerical simulation. The general conclusion of steady state flow of $\mathrm{CO}_{2}$ diffusion in heterogeneous porous media was verified by simulating Sleipner $\mathrm{CO}_{2}$-brine storage in Norway.
\end{abstract}

\section{Introduction}

Over the past few decades, $\mathrm{CO}_{2}$ concentration will increase by $2.1 \%$ per year due to human activities, and the $\mathrm{CO}_{2}$ emissions are expected to increase to 3.72 billion tons per year by 2035 from global energy ${ }^{[1]}$. According to the latest report, the global average temperature has risen by $1^{\circ} \mathrm{C}$ compared with that before the industrial revolution due to the greenhouse effect caused by $\mathrm{CO}_{2}$ emissions. It is predicted that the global average temperature will rise to $1.5^{\circ} \mathrm{C}$ in $2030-2050$ and $3^{\circ} \mathrm{C}$ in the end of this century ${ }^{[2]}$. The climate change caused by $\mathrm{CO}_{2}$ and its impact on the earth's ecosystem are becoming the main environmental challenges in this century ${ }^{[3]}$. In order to avoid this increasing trend and its consequences, CCS (carbon capture and storage) is the technology that stabilizes and reduces the concentration of carbon dioxide in the atmosphere.

In order to ensure that $\mathrm{CO}_{2}$ can be safely stored in the formation for a long time, it is necessary to know the migration mechanism of $\mathrm{CO}_{2}$ in geological structures. There are two main phenomena that occur including diffusion and advection with the process of $\mathrm{CO}_{2}$ migration in brine. Diffusion and advection will accelerate the rate of $\mathrm{CO}_{2}$ dissolution in brine, so that $\mathrm{CO}_{2}$ can be effectively and safely stored for a long time. Therefore, the analysis of multiphase flow in porous media is of great significance. In the geological structure, although the geological structure is certain, there is heterogeneity in the spatial scale due to the formation. The characteristics of the formation will be caused by the influence of random factor, and this factor will lead the randomness of $\mathrm{CO}_{2}$ migration. Therefore, the nonlinear analysis of multiphase flow must be carried out according to the randomness of formation parameters for the migration of $\mathrm{CO}_{2}$ in heterogeneous porous media.

The analysis of multiphase flow in heterogeneous porous media is usually more difficult than that of single-phase flow. Therefore, a more efficient solution is to use random processes to estimate the mean behaviour of $\mathrm{CO}_{2}$-brine two-phase flow ${ }^{[4]}$. The significant advantage of stochastic method is that the spatial heterogeneity of any reservoir is described by limited statistical properties such as mean and variance.

\section{Diffusion Equations}

The simultaneous flow of two immiscible and incompressible fluids in heterogeneous porous media is considered below. According to the mass conservation equation of CO2-brine two-phase flow[5]:

$$
\phi(\mathrm{x}) \frac{\partial S_{i}(\mathrm{x}, t)}{\partial t}-\nabla \cdot \frac{k(\mathrm{x}) k_{i}}{\mu_{i}}\left(\frac{\partial P_{i}}{\partial \mathrm{x}}-\rho g \frac{\partial D}{\partial \mathrm{x}}\right)=0, i=C O_{i} ; \text { water }
$$

Here porosity $\phi$, absolute permeability $\mathrm{k}$ are all random space functions. The control equations of $\mathrm{CO} 2-$ brine two-phase flow is changed into the stochastic partial differential equations of $\mathrm{CO} 2$-brine two-phase flow, and $\mathrm{fCO} 2$ is the fractional flow function defined as:

$$
f_{c o_{2}}=\frac{\lambda_{c o_{2}}}{\lambda_{w}+\lambda_{c o_{2}}}=\frac{k k_{r c o_{2}} / \mu_{c o_{2}}}{k k_{r w} / \mu_{w}+k k_{r c o_{2}} / \mu_{c o_{2}}}
$$

\footnotetext{
*Corresponding author: author@e-mail.org
} 


$$
q_{c o_{2}}=f_{c o_{2}}\left\{q+\lambda_{w}\left[\frac{d P_{c}}{d S_{c o_{2}}} \nabla S_{c o_{2}}+\left(\rho_{c o_{2}}-\rho_{w}\right) g\right]\right\}
$$

$\phi$ is porosity, $\mathrm{x}$ is any point in coordinate $(\mathrm{x}, \mathrm{y}, \mathrm{z}), \mu$ is viscosity, $\rho$ is density, $\mathrm{kr}$ is absolute permeability, $\mathrm{k}$ is relative permeability, $\mathrm{dP} / \mathrm{dx}$ is pressure gradient, $\mathrm{q}$ is volume rate of flow, $\mathrm{S}$ is saturation, $\mathrm{f}$ is fractional flow, $\lambda$ is mobility. Equation (1) becomes:

$\phi(\mathrm{x}) \frac{\partial S_{\omega_{2}}(\mathrm{x}, t)}{\partial t}-\nabla \cdot f_{\omega_{2}}\left\{q+\lambda_{w}\left[\frac{d P_{c}}{d S_{\omega_{2}}} \nabla S_{\omega_{2}}+\left(\rho_{\omega_{2}}-\rho_{w}\right) g\right]\right\}=0(4)$

Equation (4) is the stochastic partial differential equation of $\mathrm{CO} 2$ diffusion by the influence of heterogeneity in the reservoir. The influence of capillary pressure and gravity on $\mathrm{CO} 2$ diffusion is less than that of $\mathrm{CO} 2$ particle velocity, so it can be ignored. In order to study the influence of particle velocity on $\mathrm{CO} 2$ diffusion, the stochastic partial differential equations of particle velocity and $\mathrm{CO} 2$ saturation is needed. In the absence of capillary and gravitational effects, $\mathrm{CO} 2$ fractional flow $\mathrm{f}$ can be replace by $\mathrm{CO} 2$ saturation $\mathrm{S}$ :

$$
\nabla f_{\omega_{2}}=f_{\omega_{2}}^{\prime}\left(S_{\omega_{2}}\right) \nabla S_{\omega_{2}}=\left(d f_{\omega_{2}} / d S_{\omega_{2}}\right) \nabla S_{\omega_{2}} \Leftrightarrow \frac{\partial f_{\omega_{2}}}{\partial \mathrm{x}}=\frac{\partial f_{\omega_{2}}}{\partial S_{\omega_{2}}} \cdot \frac{\partial S_{\omega_{2}}}{\partial \mathrm{x}}(5)
$$

Equation (4) can rewrite as:

$$
\frac{\partial S_{c o_{2}}(\mathrm{x}, t)}{\partial t}+f_{c o_{2}}^{\prime}\left(S_{c o_{2}}\right) \frac{q(\mathrm{x}, t)}{\phi(\mathrm{x})} \nabla S_{c o_{2}}(\mathrm{x}, t)=0
$$

$\mathrm{v}(\mathrm{x})=\mathrm{q}(\mathrm{x}, \mathrm{t}) / \phi(\mathrm{x})$ is $\mathrm{CO} 2$ particle velocity, Equation (6) is a nonlinear stochastic partial differential equation composed of random variables. It can be seen as a stochastic process of $\mathrm{CO} 2$ diffusion in heterogeneous porous media. It can be described by probability density function and joint probability density moment (mean and variance) in order to quantify the stochastic process:

$$
\begin{gathered}
v_{c o_{2}}\left(S_{c o_{2}}, \mathrm{x}, t\right)=\left\langle v_{c o_{2}}\left(S_{c o_{2}}, \mathrm{x}, t\right)\right\rangle+v_{c o_{2}}^{\prime}\left(S_{c o_{2}}, \mathrm{x}, t\right) \\
S_{c o_{2}}(\mathrm{x}, t)=\left\langle S_{c o_{2}}(\mathrm{x}, t)\right\rangle+S_{c o_{2}}^{\prime}(\mathrm{x}, t)
\end{gathered}
$$

$<>$ represents ensemble mean, the first derivative represents variance, which is the range.

\section{Diffusion of Sleipner}

\subsection{Geological Characteristics}

Utsira reservoir in Sleipner project in Norway is selected as the research object in order to study the diffusion of CO2-brine two-phase flow in heterogeneous actual formation. It is $450 \mathrm{~km}$ long, $75-130 \mathrm{~km}$ wide, with an area of about $26100 \mathrm{~km} 2$, and located between $700 \mathrm{~m}$ and $1000 \mathrm{~m}$ below sea level[6]. The formation composition of the target block is mainly sandstone[7]. The results of modal analysis on core of Utsira reservoir show that the porosity of the reservoir is generally between $27 \%$ and
$42 \%$ [8]. The permeability of Utsira reservoir measured by horizontal and vertical core samples is between $1.5 \mathrm{D}$ and 3.2D[9]. Thus, the initial conditions, fluid and reservoir properties are shown in Table 1:

Table 1. The initial conditions, fluid and reservoir properties ${ }^{[6-9]}$

\begin{tabular}{|c|c|c|}
\hline Parameter & Value & Unit \\
\hline Length of formation & 50 & {$[\mathrm{~m}]$} \\
\hline Cross-section area & 1 & {$\left[\mathrm{~m}^{2}\right]$} \\
\hline Temperature & 40 & {$\left[{ }^{\circ} \mathrm{C}\right]$} \\
\hline Pressure & 10 & {$[\mathrm{MPa}]$} \\
\hline $\begin{array}{c}\text { Viscosity of brine } \\
{[\mathrm{Pa} \cdot \mathrm{s}]}\end{array}$ & $6.6 \times 10^{-3}$ \\
\hline $\begin{array}{c}\text { Viscosity of CO } 2 \\
{[\mathrm{~Pa} \bullet \mathrm{s}]}\end{array}$ \\
\hline $\begin{array}{c}\text { The mean of porosity } \\
{\left[\begin{array}{c}\text { The variance of } \\
\text { porosity }\end{array}\right.}\end{array}$ & 0.35 & {$[-1-0.3$} \\
\hline $\begin{array}{c}\text { The correlation scale of } \\
\text { porosity }\end{array}$ & $(1-2) \times 10^{-3}$ & {$[\mathrm{~m}]$} \\
\hline $\begin{array}{c}\text { Absolute permeability } \\
{[\mathrm{d}]}\end{array}$ & $1-2$ & {$[\mathrm{D}]$} \\
\hline $\begin{array}{c}\text { Injection rate } \\
{\left[\mathrm{m}^{3} / \mathrm{s}\right]}\end{array}$ \\
\hline $\begin{array}{c}\text { Velocity } \\
\text { Time }\end{array}$ & $5 \times 10^{-3}$ & $1 \times 10^{-3}$ \\
\hline
\end{tabular}

\subsection{Numerical Simulation}

In Utsira reservoir, the joint probability distribution and the joint statistical moment (mean value and variance) were used to quantify the change process of brine saturation under the influence of formation heterogeneity. The mathematical model of $\mathrm{CO} 2$ diffusion travel at the case of two-dimensional steady-state flow is established, and it is assumed that brine fills the reservoir. The simulation results are shown as follow:

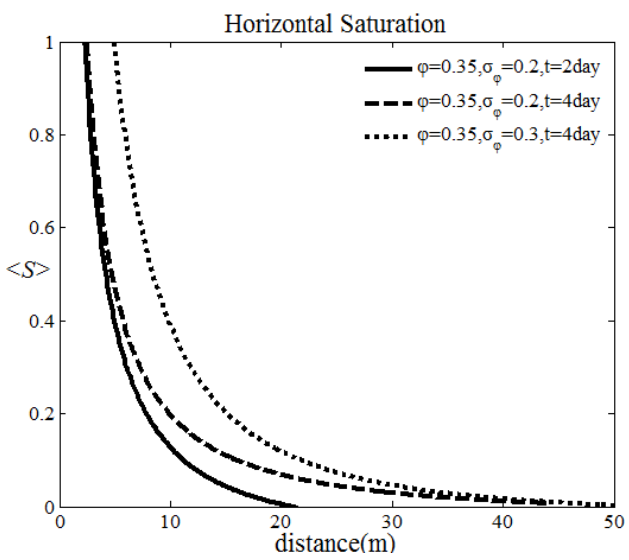

(a) 


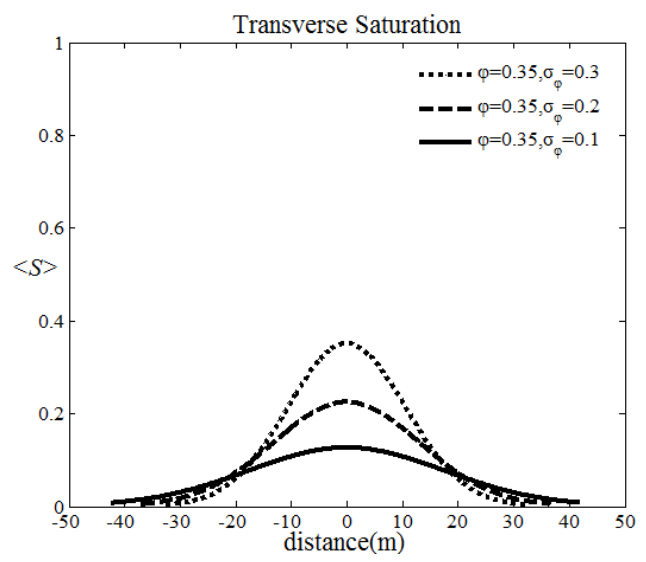

(b)

Fig. 1. (a) the horizontal saturation profile of $\mathrm{CO}_{2}$ particle travel and (b) shows the transverse saturation profile of $\mathrm{CO}_{2}$ particle travel. The diffusion of $\mathrm{CO}_{2}$ in Utsira reservoir.

It can be seen from figure (a), when the average porosity is 0.35 and the porosity variance is $0.2, \mathrm{CO} 2$ particle travels for 2 days with the diffusion distance of $21 \mathrm{~m}$, and $\mathrm{CO} 2$ particle travels for 4 days with the diffusion distance of $44 \mathrm{~m}$. When the variance of porosity is changed to 0.3 , the $\mathrm{CO} 2$ particle travels for 4 days and the diffusion distance increases to $50 \mathrm{~m}$. It is indicated that the heterogeneity of the pores affects the $\mathrm{CO} 2$ diffusion farther away with the time increases. When the variance of porosity was 0.3 , the saturation starts to change later than when the variance of porosity was 0.2 . This indicates the effect of the heterogeneity of the pores on the occurrence time of the diffusion of $\mathrm{CO} 2$. The later $\mathrm{CO} 2$ diffusion occurs due to the increase of the variance of porosity. It is affected by the heterogeneity of pore, such as the size of pore, the trajectory of $\mathrm{CO} 2$ particle, and the friction between $\mathrm{CO} 2$ particle and the pore.

It can be seen from figure (b), when the average value of porosity is 0.35 , the variance of the porosity are $0.1,0.2$ and 0.3 respectively, and the normal distribution formed by the transverse saturation profile increases gradually. As the $\mathrm{CO} 2$ particle diffusion began, the increase of variance of porosity leads to the increase of its saturation variation. All these prove that the heterogeneity of porous media quantified by mean and variance has a significant effect on the diffusion of $\mathrm{CO} 2$.

\subsection{Analysis of influencing factors of storage}

\subsubsection{Analysis of Relative Permeability}

In this section, the rules of relative permeability in diffusion were quantitatively analyzed through the simulation results of the saturation changes in heterogeneous actual formation. The simulation is carried out for different variances of porosity, and the simulation results are shown as follows:

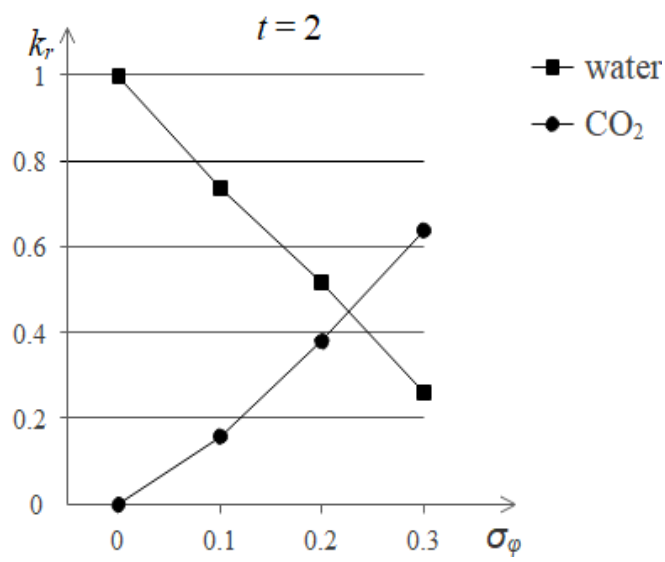

(a)

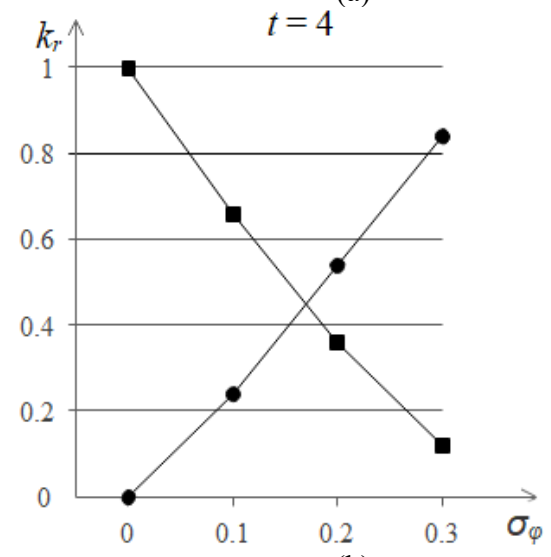

(b)

Fig. 2. (a) $t=2$ day $\mathrm{CO}_{2}$ diffusion and (b) $t=4$ day $\mathrm{CO}_{2}$ diffusion. Relative permeability curves.

It can be seen from the estimated results that when $\mathrm{t}$ $=2$ day, the relative permeability of $\mathrm{CO} 2$ diffusion is gradually increasing with the increase of variance of porosity, and when $t=4$ day, the relative permeability of $\mathrm{CO} 2$ diffusion is increasing more rapidly with the increase of variance of porosity compared with $t=2$ day. This indicates that the diffusion of $\mathrm{CO} 2$ is accelerated with the increase of variance of porosity in the porous media, and the fluidity of $\mathrm{CO} 2$ is improved. This causes more unsaturated brine is in contact with $\mathrm{CO} 2$, and more $\mathrm{CO} 2$ is dissolved in the brine so that improve the $\mathrm{CO} 2$ dissolved storage.

\subsubsection{Analysis of Capillary Pressure}

In this section, the rules of capillary pressure in diffusion were quantitatively analyzed through the simulation results of the saturation changes in heterogeneous actual formation. The simulation is carried out for different variances of porosity, and the simulation results are shown as follows: 


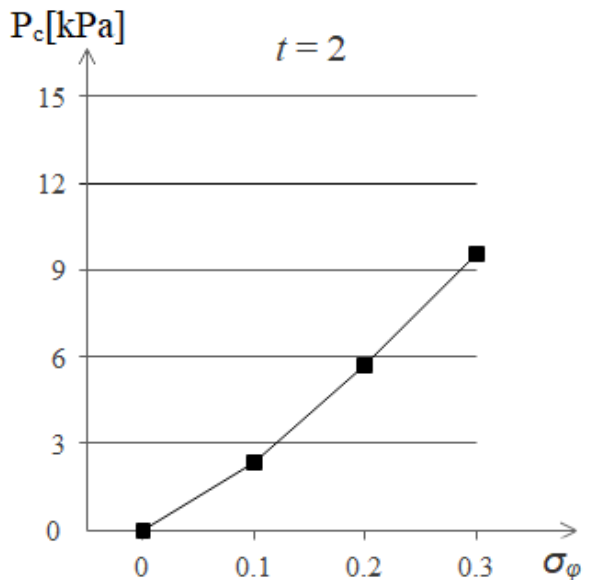

(a)

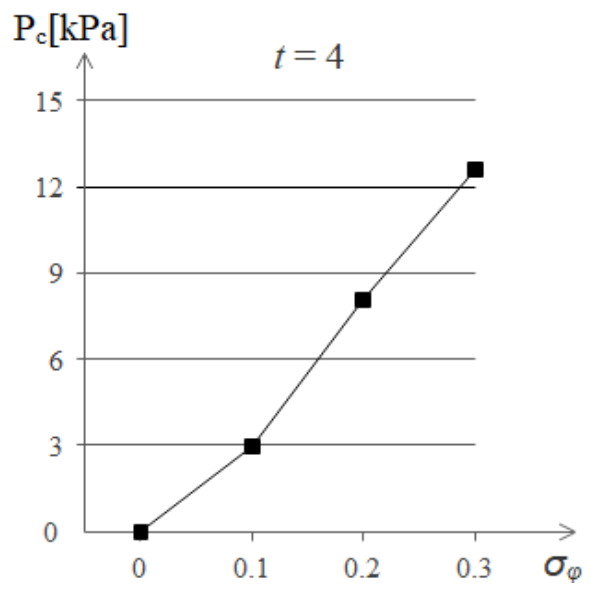

(b)

Fig. 3. (a) $t=2$ day $\mathrm{CO}_{2}$ diffusion and (b) $t=4$ day $\mathrm{CO}_{2}$ diffusion. Capillary pressure curves.

It can be seen from the estimation results that when $\mathrm{t}$ $=2$ day, the capillary pressure of $\mathrm{CO} 2$ diffusion gradually increases with the increase of variance of porosity, and finally reaches $9.6 \mathrm{kPa}$. When $\mathrm{t}=4 \mathrm{day}$, capillary pressure curve of $\mathrm{CO} 2$ diffusion increases faster and finally reaches $12.6 \mathrm{kPa}$ compared with $\mathrm{t}=2$ day. It shows that with as time goes on, the spread of $\mathrm{CO} 2$ is more and more extensive, and more and more $\mathrm{CO} 2$ is dissolved in brine. $\mathrm{CO} 2$ dissolved in brine will increase the concentration of brine and accelerate the diffusion. The change of porosity accelerates the diffusion of $\mathrm{CO} 2$ in the porous media, promotes the contact between $\mathrm{CO} 2$ and more brine. This will increase the dissolution rate of $\mathrm{CO} 2$ in brine, and increase the capillary pressure in the pore. Finally, the amount of $\mathrm{CO} 2$ stored increases in the porous media, and then the residual storage of $\mathrm{CO} 2$ increases.

\section{Summary}

The diffusion of $\mathrm{CO} 2$ particle in heterogeneous porous media is studied in this paper. The equations of $\mathrm{CO} 2$ diffusion in heterogeneous porous media are established at the case of CO2-brine two-phase steady flow. The average behaviour of $\mathrm{CO} 2$ diffusion is estimated by stochastic process. The randomness of the mean and variance of CO2-brine two-phase flow saturation was quantified by stochastic process analysis with joint density distribution and joint statistical moment. The general conclusion of steady state flow of $\mathrm{CO} 2$ diffusion in heterogeneous porous media was verified by simulating Sleipner CO2-brine storage in Norway.

\section{Acknowledgment}

This work is supported by National Natural Science Foundation of China under Grant No. 41602134, Project funded by China Postdoctoral Science Foundation under Grant No. 2017T100223, Natural Science Foundation of Heilongjiang Province under Grant No. YQ2019D001.

\section{References}

1. Cambridge University Press. "Climate change 2007: impacts, adaptation and vulnerability." journal of environmental quality37.6(2007):2407

2. Edenhofer, O., R. Pichs-Madruga, Y. Sokona, E. Farahani, S. Kadner, K. Seyboth, A. Adler, I. Baum, S. Brunner and P. Eickemeier. "IPCC, 2018: Climate change 2018: Mitigation of climate change." Presentación en Edenhofer, Co-presidente, IPCC Working Group III. (2018)

3. Allen, Simon K, et al. "Climate Change 2013: The Physical Science Basis. An overview of the Working Group 1 contribution to the Fifth Assessment Report of the Intergovernmental Panel on Climate Change (IPCC). " computational geometry 18.2(2007):95-123

4. Evangelos, K., and Paleologos. "Stochastic Methods for Flow in Porous Media, Coping With Uncertainties." Eos Transactions American Geophysical Union (2003)

5. Bear, and Jacob. "Dynamics of Fluids in Porous Media. " Soil Science 120.2(1975):162-163

6. Semere Solomon, The Bellona Foundation. "Carbon Dioxide Storage: Geological Security and Environmental Issues - Case Study on the Sleipner Gas Field in Norway Summary." bellona report (2006)

7. Eidvin T, Rundberg Y, Smelror M. Revised chronology of Neogene sands (Utsira and Skade Formations) in the central and northern North Sea. Onshoreoffshore relationships on the North Atlantic Margin. (2002)

8. Pearce J M, Kemp S J, Wetton P D. Mineralogical and Petrographical Characterisation of a $1 \mathrm{~m}$ Core from the Utsira Formation, Central North Sea: British Geological Survey Report WG/99/024. British Geological Survey. (1999)

9. Zweigel, P., et al. "Reservoir geology of the Utsira Formation at the first industrial-scale underground $\mathrm{CO} 2$ storage site (Sleipner area, North Sea)." geological storage of carbon dioxide 523.7558(2004):96-100 